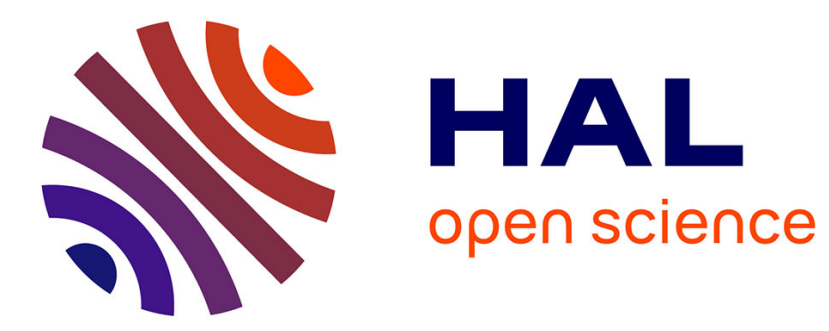

\title{
High-precision helium isotope measurements in air
}

\author{
J Mabry, T.F. Lan, P.G. Burnard, Bernard Marty
}

\section{To cite this version:}

J Mabry, T.F. Lan, P.G. Burnard, Bernard Marty. High-precision helium isotope measurements in air. Journal of Analytical Atomic Spectrometry, 2013, 10.1039/c3ja50155h . hal-01346316

\section{HAL Id: hal-01346316 https://hal.science/hal-01346316}

Submitted on $20 \mathrm{Jul} 2016$

HAL is a multi-disciplinary open access archive for the deposit and dissemination of scientific research documents, whether they are published or not. The documents may come from teaching and research institutions in France or abroad, or from public or private research centers.
L'archive ouverte pluridisciplinaire HAL, est destinée au dépôt et à la diffusion de documents scientifiques de niveau recherche, publiés ou non, émanant des établissements d'enseignement et de recherche français ou étrangers, des laboratoires publics ou privés. 


\title{
High-precision helium isotope measurements in air
}

\author{
Jennifer Mabry, ${ }^{a}$ Tefang Lan, ${ }^{a}$ Pete Burnard ${ }^{a}$ and Bernard Marty ${ }^{a}$ \\ Received (in $X X X, X X X) X$ th $X X X X X X X X X 20 X X$, Accepted $X$ th $X X X X X X X X X 20 X X$ \\ DOI: $10.1039 / b 000000 x$
}

${ }_{5}$ Helium has two natural isotopes which have contrasted, and variable sources and sinks in the atmosphere $\left({ }^{3} \mathrm{He} /{ }^{4} \mathrm{He}_{\text {air }}=1.382 \pm 0.005 \times 10^{-6}\right)$. Variations in atmospheric helium isotopic composition may exist below typical measurement precision thresholds $(0.2$ to $0.5 \%, 2 \sigma)$. In order to investigate this possibility, it is necessary to be able to consistently measure helium isotopes in air with high precision (below $0.2 \%$ $2 \sigma$ ). We have created an air purification and measurement system that improves the helium isotope 10 measurement precision. By purifying a large quantity of air at the start of a measurement cycle we can make rapid standard-bracketed measurements. Controlling the amount of helium in each measured aliquot minimizes pressure effects. With this method we improve the standard errors by $2 \mathrm{x}$ over measuring the same amount of gas in a single step. Individual measurements have standard errors of 0.2 to $0.3 \%$ ( $2 \sigma)$, with three repeat samples needed to reach $0.1 \%$ or better errors. The long-term reproducibility of our 15 calibration sample is $0.033 \%(2 \sigma)$.

\section{Introduction}

The atmospheric content of helium (5.24 ppm vol. $\left.{ }^{1}\right)$ is much lower than would be predicted from degassing of the mantle and crust because helium escapes from the atmosphere through 20 thermal and non-thermal processes ${ }^{2}$. Therefore, the atmospheric abundance of its two natural isotopes, ${ }^{3} \mathrm{He}$ and ${ }^{4} \mathrm{He}$, results from a balance of outgassing of the solid earth, input from precipitation of solar wind at the poles, and loss into space, with a residence time on the order of $10^{6}$ years $^{3}$. The isotopic composition of the 25 atmosphere $\left({ }^{3} \mathrm{He} /{ }^{4} \mathrm{He}=1.382 \pm 0.005 \times 10^{-6}\right)^{4}$ is distinctly different from crustal helium $\left({ }^{3} \mathrm{He} /{ }^{4} \mathrm{He} \sim 10^{-8}\right)$ which is dominated by radiogenic ${ }^{4} \mathrm{He}$ produced during the alpha decays of crustal $\mathrm{U}$ and Th. Several authors ${ }^{5-7}$ have proposed that the amount of excess crustal helium entering the atmosphere due to modern 30 fossil fuel extraction may be enough to upset the balance of the helium composition in the atmosphere on a timescale short enough to detect with modern measurement techniques.

Several groups have searched for evidence of temporal ${ }^{6-12}$ variations in the helium isotopic composition of the atmosphere, 35 however results thus far have not been definitive. Groups ${ }^{6,7,11}$ measuring pre-industrial samples report elevated ${ }^{3} \mathrm{He} /{ }^{4} \mathrm{He}$ relative to modern air by as much as $4 \%$, but the errors associated with these measurements are typically quite large, up to $50 \%$. Groups searching for temporal variations on a shorter, decadal scale have 40 found a range of results from no change at the $0.2 \%(2 \sigma)$ level $^{10}$, to a decrease of the atmospheric ${ }^{3} \mathrm{He} /{ }^{4} \mathrm{He}$ of $(0.023 \pm$ $0.008) \% /$ year $^{12}$ up to $(0.094 \pm 0.156) \% /$ year $^{9}$. In order to resolve these discrepancies will require further improvement in the precision of ${ }^{3} \mathrm{He} /{ }^{4} \mathrm{He}$ measurements from air samples.

45 Obtaining such a high level of precision (below 0.2\%) for helium measurements presents several analytical challenges. The low abundance of helium in the atmosphere means that large quantities of air must be well-purified to obtain a reasonable helium signal and that static mass spectrometry must be used.

50 High-sensitivity noble gas ion sources are notorious for being pressure sensitive, which means it is imperative to closely match the amounts of gas measured in each sample or standard aliquot. There are six orders of magnitude difference in abundance of the two isotopes of helium, making simultaneous detection ${ }_{55}$ challenging. Finally, ${ }^{3} \mathrm{He}$ has several isobars, which must either be resolved or corrected for.

In this paper, we detail the system we have developed in order to mitigate these challenges. It features a unique standard-sample bracketing system that will mimic as closely as possible the rapid ${ }_{60}$ switching between standard and sample which is possible with dynamic mass spectrometry. Our system allows the purification and preparation of enough sample gas for multiple analyses of the same sample, thus gaining some of the benefits of the dynamic system. Additionally, the amount of helium in each sample ${ }_{65}$ aliquot is matched to the amount in an aliquot of the standard to minimize pressure effects. Data acquired by this method are compared to the more standard measurement technique of measuring all of the purified sample in a single aliquot for statistical comparison. 


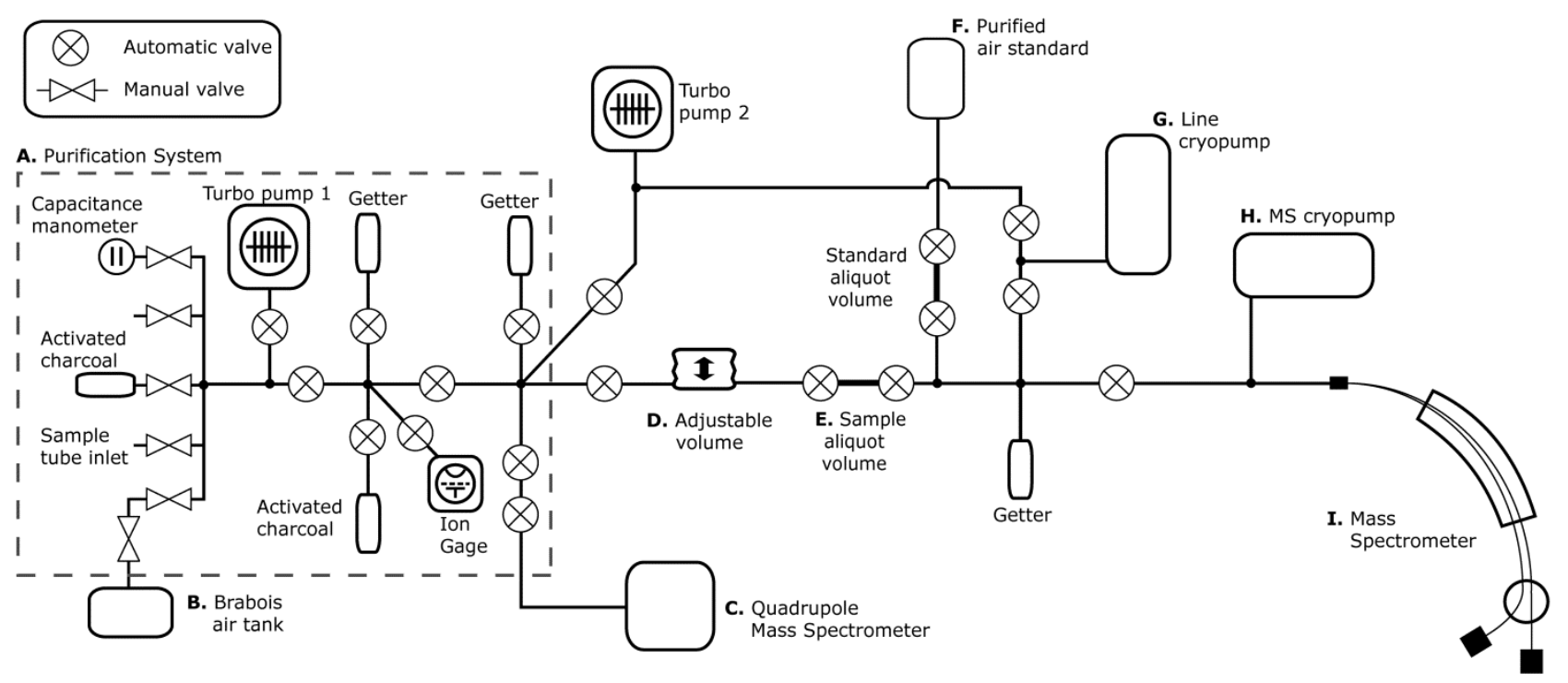

Fig. 1 Schematic of the sample purification and inlet system.

\section{Method}

\section{Sample Gas Purification}

${ }_{5}$ We purify a relatively large amount of air sample $\left(\sim 15-20 \mathrm{~cm}^{3}\right)$ all at once before any measurements are made. The air is first exposed to activated charcoal held at $77 \mathrm{~K}$ (liquid nitrogen temperature) to trap the majority of the unwanted gases including the heavier non-reactive gases such as argon. Then the remaining 10 gas is sequentially exposed to two hot $(400 \mathrm{C})$ titanium getters which chemically trap reactive gases and to an additional activated charcoal finger (Fig. 1A). Each step lasts ten minutes.

In order to monitor the consistency of the purification from sample to sample, we separate a small amount of the purified gas 15 and analyze it with a quadrupole mass spectrometer (MKS Microvision $2^{\mathrm{TM}}$, Fig. 1C). After purification, each sample consists of $>98 \%$ neon and helium isotopes and $<2 \%$ impurities (such as $\mathrm{H}_{2}, \mathrm{~N}_{2}$ and $\mathrm{CO}_{2}$ ). Regular repetitions show no significant variations.

20 The purified sample is then held in an adjustable volume (Fig. 1D) with a pipette (Fig. 1E) which is used to take multiple aliquots and perform standard-sample bracketing. Repeated measurements draw on the same reservoir of purified sample, which is important, as typically using a "standard bracketing"

25 method with static mass spectrometry actually means using a newly purified sample for each measurement ${ }^{13}$.

\section{Running Standard and Sample Air}

The standard we used for our standard bracketing measurements
30 is a bottle of purified air obtained from the Bretagne region of France, just on the shore of the Atlantic. A 2.3L volume of air was collected in a steel tank and passed through silica gel to remove some of the water. This gas was later purified in the lab. The air was sequentially exposed to two titanium getters $(\sim 800 \mathrm{C})$ 35 for approximately 125 hours and then to cold (77K) activated charcoal for 2.5 hours. Finally the gas was expanded into a $10 \mathrm{~L}$ bottle with a $0.1 \mathrm{~cm}^{3}$ pipette for use. Twice, we expanded this bottle to a portion of our extraction line for approximately 15 hours in order to expose it to activated charcoal and remove 40 further traces of argon and other impurities.

For the sample measurements described in this paper we use air that was collected in a $2.3 \mathrm{~L}$ tank from a park on a bluff near the CRPG Institute: Parc de Brabois, Villers-lès-Nancy, France $(48.661 \mathrm{~N}, 6.149 \mathrm{E})$. This location is $85 \mathrm{~km}$ from the closest 45 nuclear power plant; the closest industrial plant is a steel factory about $7 \mathrm{~km}$ away. This bottle is connected to an $\sim 7 \mathrm{~cm}^{3}$ pipette volume. From this tank we draw approximately $20 \mathrm{~cm}^{3}$ (3 pipettes to start, increasing as the tank becomes depleted) of air for each measurement. This volume is sufficient to take multiple 50 measurement aliquots from each sample after purification.

We used an air standard, rather than an artificially mixed standard which could have a higher ${ }^{3} \mathrm{He}$ content (and thus lower error associated with our calibrations), because we wanted the standard and sample to be as close as possible in composition to 55 eliminate biases in the mass spectrometer. However, despite precautions, the standard gas is fractionated relative to Brabois air, being depleted in ${ }^{3} \mathrm{He}$ by $3.6 \%$. This fractionation was discovered early on in the life of the standard and has remained stable over time. Thus we believe that it occurred during the 
preparation of the standard.

We have considered several possible sources of this fractionation and found them all to be improbable. The long times during purification make it unlikely that a light gas such as 5 helium would be fractionated by thermal diffusion. We also considered thermophoresis, which can cause steady state concentration gradients under some conditions, but this effect should be negligibly small for helium atoms at atmospheric or lower pressure ${ }^{14}$. Finally, the possibility that large enough 10 quantities of helium were adsorbed on the silica gel at room temperature to cause such a level of fractionation is not plausible $^{15}$. Thus further experiments would be needed to determine the cause of the fractionation, which is beyond the scope of this work.

\section{${ }_{15}$ Pressure Effect}

It is essential to control the amount of gas let into the mass spectrometer with each measurement, because the ion source (Nier-type) is extremely sensitive to pressure ${ }^{16}$. For example, in measuring multiples of our standard, we found the measured

$20{ }^{3} \mathrm{He} /{ }^{4} \mathrm{He}$ ratio changes nonlinearly by about $13 \%$ for a 20 -fold increase in the ${ }^{4} \mathrm{He}$ amount (Fig. 2). Mitigating this effect was one of the major considerations when designing this new method, and we approach the problem in two steps.

First, the volume where the purified sample gas is held is 25 adjustable, consisting of a bellows connected to a stepper motor which is computer controlled. This serves two purposes: (1) to allow us to match the amount of gas in a sample aliquot with the size of an aliquot of our standard (since different samples can have different amounts) and (2) to compensate for the depletion 30 of the reservoir as aliquots are pulled out and the pressure decreases. Carefully matching the size of each sample aliquot to the standard and previous sample aliquots bypasses the need for a pressure correction in the data. In practice we found that keeping the ${ }^{4} \mathrm{He}$ amount of the sample within $2 \%$ of the standard amount 35 was close enough to eliminate the pressure effect. This level was chosen because there are no correlations with amount seen at this level (Fig. 3). At the $10 \%$ variation, there is a clear correlation between the amount and the ratio, but this disappears at the $2 \%$ level.

40

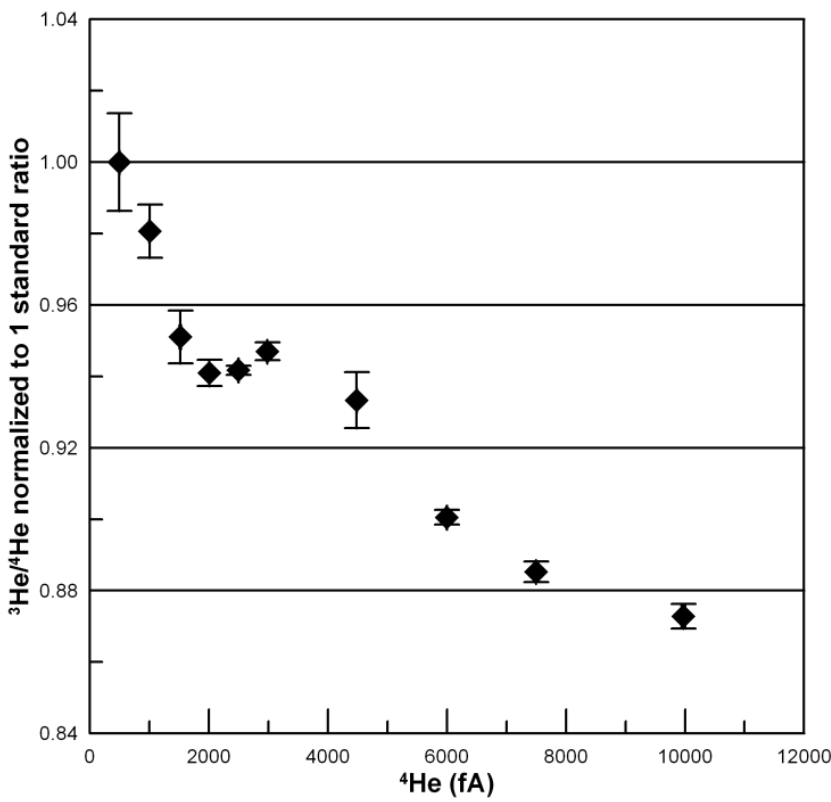

Fig. 2 Effect of the pressure in the mass spectrometer on the measured ${ }^{3} \mathrm{He} /{ }^{4} \mathrm{He}$ ratio. The ratio decreases nonlinearly by about $13 \%$ for a 20 -fold increase in ${ }^{4} \mathrm{He}$ amount.

45 Second, we expose both the sample gas and standard gas to a cryogenic trap (Oxford ICE, Fig. 1G) to remove the neon before admittance to the mass spectrometer. The trap is set to $35 \mathrm{~K}$ (uncalibrated temperature, set point determined experimentally where most neon is trapped without trapping helium) and is stable ${ }_{50}$ to $\pm 0.01 \mathrm{~K}$. This keeps the pressure in the mass spectrometer as low and as consistent as possible.

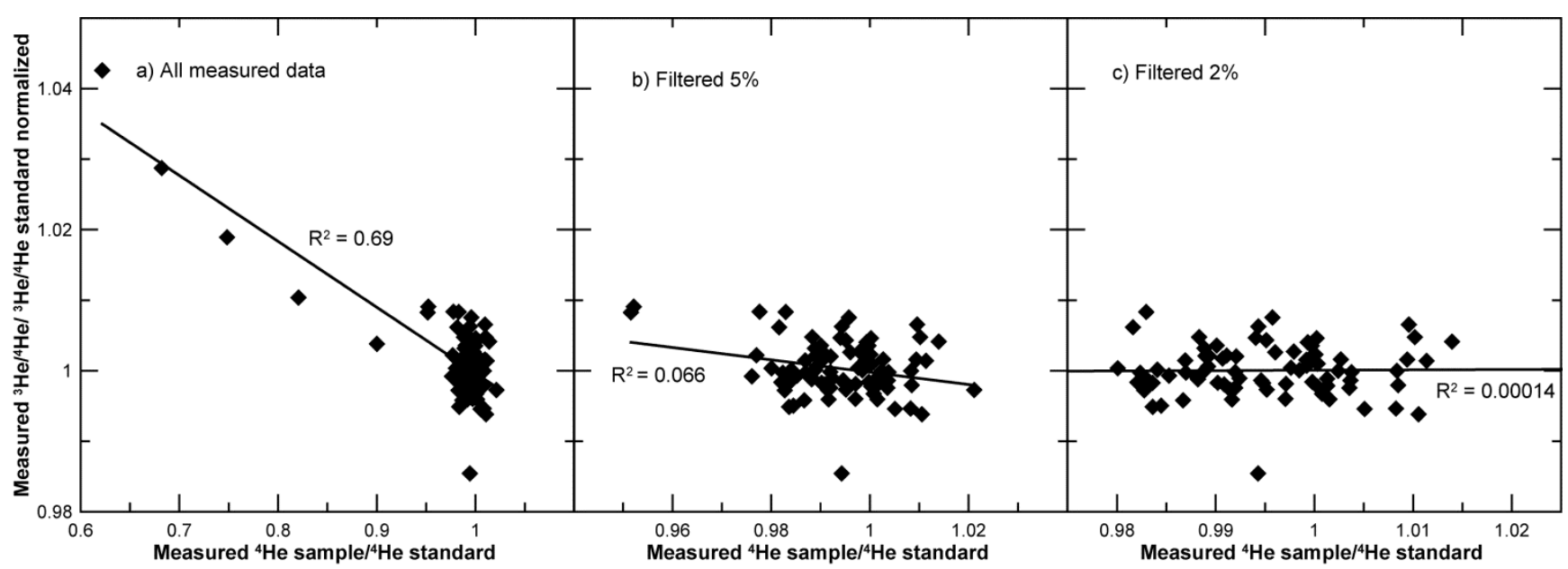

Fig.3 Measured ${ }^{3} \mathrm{He} /{ }^{4} \mathrm{He}$ ratio for different varying amounts of ${ }^{4} \mathrm{He}$ relative to the internal standard: a) all measurements, some which have $40 \%$ 55 different ${ }^{4} \mathrm{He}$ amount from the standard; b) filtering out points more than $5 \%$ away from the standard amount; and c) filtering out points more than $2 \%$ away from the standard amount. At the $10 \%$ level, there is a clear correlation between the amount and the ratio, but this disappears at the $2 \%$ level. 

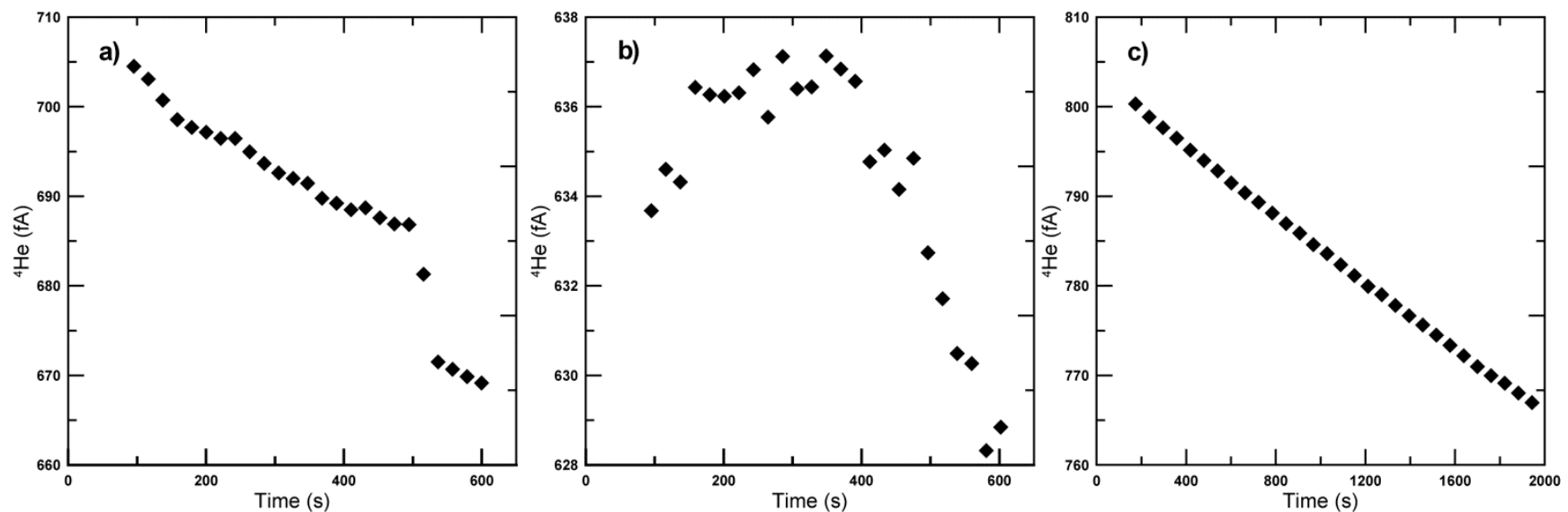

Fig. 4 Single measurements of ${ }^{4} \mathrm{He}$ with an activated charcoal finger on the mass spectrometer volume: (a) adding roughly $2 \mathrm{~cm}$ of liquid $\mathrm{N}_{2}$ near end of the measurement, (b) without any liquid $\mathrm{N}_{2}$, and (c) after replacing the charcoal finger with a cryogenic trap.

\section{Mass Spectrometer}

Measurements are made on a new Thermo Helix Split Flight Tube (SFT) multi-collector noble gas mass spectrometer, which was installed in February 2012. This machine is designed for 10 helium isotope measurements with a split flight tube which physically separates the ${ }^{3} \mathrm{He}$ and ${ }^{4} \mathrm{He}$ beams. The two paths terminate in an electron multiplier and Faraday cup to allow for simultaneous detection of ${ }^{3} \mathrm{He}$ and ${ }^{4} \mathrm{He}$. The mass resolution of the multiplier is $\sim 700$ which is sufficient to resolve ${ }^{3} \mathrm{He}$ isobars

15 (HD and $\left.{ }^{3} \mathrm{H}\right)$, and the resolution of the Faraday cup is 425 . An electrostatic filter before the multiplier helps to further improve isotope separation and block out stray ions. The helium sensitivity is $2.35 \times 10^{-4} \mathrm{~A} /$ torr at $400 \mu \mathrm{A}$ trap current. We typically operate at $350 \mu \mathrm{A}$ trap current and $4500 \mathrm{~V}$ acceleration 20 voltage.

An SAES getter installed on the mass spectrometer volume keeps hydrogen levels low which reduces the amount of HD interference at mass 3. Previously, a charcoal finger was used to keep the background of argon and other heavier isotopes low

25 during a static measurement. However, we found that for these measurements, it was not stable enough and the small pressure changes resulting from modest changes to the liquid nitrogen level were enough to disrupt the measurement (Fig. 4). For example, the addition of approximately $2 \mathrm{~cm}$ of liquid $\mathrm{N}_{2}$ could 30 change the sensitivity of the ${ }^{4} \mathrm{He}$ measured by $2 \%$ (Fig. 4a). Filling the liquid $\mathrm{N}_{2}$ only before an analysis (and not during) sometimes worked, but could have unpredictable effects depending on the length of the analysis and the temperature in the room which would change how much evaporation occurred over 35 the course of the measurement. Abandoning liquid $\mathrm{N}_{2}$ altogether (Fig. 4b) made for very unstable measurements. These problems disappeared with the replacement of the charcoal finger by the cryogenic trap (Fig. 4c). This trap is set to $25 \mathrm{~K}$ (uncalibrated temperature, set point determined experimentally at lowest 40 temperature not trapping helium) and is stable to $\pm 0.05 \mathrm{~K}$.

\section{Measurements and Results}

In order to evaluate whether the changes to our extraction line and measurement method led to a real improvement in the 45 statistics of the measured data, we performed two different sets of measurements over the course of three months. All of these measurements were made using the Brabois (local air) sample gas tank as described above.

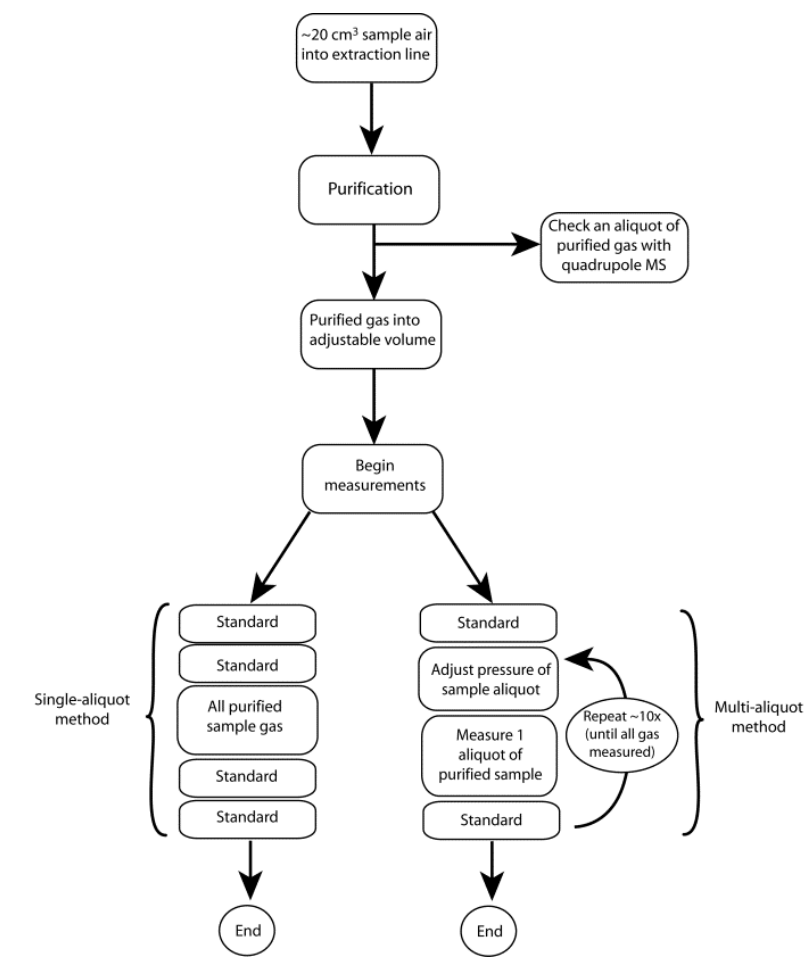

Fig. 5 Flow diagram of the procedure for the single-aliquot and multialiquot methods.

We made a set of measurements employing the multiple standard bracketed technique described above, making multiple ${ }_{55}$ measurements of each sample. And to compare with this, we also made measurements in the 'classic' way by purifying the same 
amount of sample gas but then letting all of the gas into the mass spectrometer for a single measurement of each sample, also bracketed by measurements of the standard. These will be referred to as the multi-aliquot and single-aliquot methods 5 respectively. The initial procedure such as gas purification is identical for both methods, only the measurement procedure differs (Fig. 5). The total amount of gas measured by each method is approximately the same, however the total time of the measurement is much less for the single-aliquot method: $\sim 15$ 10 minutes for the single-aliquot vs $\sim 150$ minutes over all measurements for the multi-aliquot method.

\section{Multi-Aliquot Measurements}

To perform the multi-aliquot measurements, approximately 20 $\mathrm{cm}^{3}$ of air is purified and passed through the extraction line to the 15 bellows volume as described above. A small aliquot of this gas is quickly measured in the mass spectrometer to determine the pressure of $\mathrm{He}$ in the bellows volume and then the bellows position is adjusted such that the amount of ${ }^{4} \mathrm{He}$ in one aliquot is within $2 \%$ of the amount in one pipette of the standard. Once this 20 is reached, the measurement proceeds with multiple sample aliquots being drawn out from the bellows volume for separate measurements, each one bracketed by standard measurements (Fig. 5). The total time for sample preparation and measurement is around 9 hours.

25 Table 1 Multi-aliquot measurement data. Shown are the total number of measurements $(\mathrm{N})$, the average measured ${ }^{4} \mathrm{He}$ relative to the standard $\left(\mathrm{A}_{\mathrm{m}}\right)$, the average ${ }^{3} \mathrm{He} /{ }^{4} \mathrm{He}$ relative to the standard $\left(\mathrm{R}_{\mathrm{m}}\right)$, and the standard error $(2 \sigma)$.

$\begin{array}{cccc}\mathbf{N} & \mathbf{A}_{\mathbf{m}} & \mathbf{R}_{\mathbf{m}} & \text { Standard error (2) }) \\ 11 & 0.9910 & 1.0387 & 0.0022 \\ 11 & 1.0116 & 1.0359 & 0.0031 \\ 10 & 0.9923 & 1.0356 & 0.0017 \\ 8 & 1.0041 & 1.0354 & 0.0033 \\ 8 & 0.9810 & 1.0354 & 0.0032 \\ 11 & 1.0045 & 1.0372 & 0.0029 \\ 11 & 1.0138 & 1.0364 & 0.0029 \\ 11 & 1.0043 & 1.0368 & 0.0026 \\ 9 & 1.0079 & 1.0346 & 0.0021 \\ 11 & 0.9991 & 1.0346 & 0.0012 \\ 6 & 1.0071 & 1.0352 & 0.0043 \\ 11 & 0.9882 & 1.0361 & 0.0022 \\ 11 & 0.9921 & 1.0377 & 0.0020 \\ 11 & 0.9914 & 1.0361 & 0.0037 \\ 11 & 0.9883 & 1.0378 & 0.0022 \\ 9 & 0.9960 & 1.0367 & 0.0019 \\ 11 & 0.9991 & 1.0379 & 0.0027 \\ 11 & 0.9955 & 1.0355 & 0.0033 \\ 11 & 0.9862 & 1.0363 & 0.0030 \\ & & \mathbf{1 . 0 3 6 3} \pm \mathbf{0 . 0 0 0 5}(\mathbf{0 . 0 5 1 \% )}-\text { standard error } \\ & & \pm \mathbf{0 . 0 0 2 3}(\mathbf{0 . 2 2} \%)-\text { standard deviation }\end{array}$

30

Table 1 summarizes the measurements made by the multialiquot method. The quantity $A_{m}$ in Table 1 represents how closely the amount of helium in the sample measurements is matched to the standard. First, the aliquot amount, $A_{a}$, is ${ }_{35}$ calculated, as the measured ${ }^{4} \mathrm{He}$ of the sample aliquot, divided by the average of the amounts in the standards measured immediately before and after the sample aliquot:

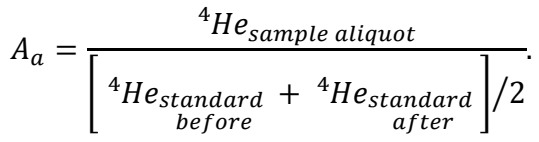

Then for each sample, the average of all of the individual $\mathrm{A}_{a}$ are made to give the final for the sample: $A_{m}=\left(\sum_{1}^{N} R_{a N}\right) / N$, where ${ }_{40} N$ is the number of standard-bracketed aliquots measured from that sample. Typically, it is possible to measure 11 aliquots from one sample, however if the value of $A_{a}$ was greater than 1.02 or less than 0.98 (i.e. if the amount of ${ }^{4} \mathrm{He}$ in a sample aliquot differed than the standard by more than $\pm 2 \%$ ), then that 45 measurement was thrown out.

The ratios, $R_{m}$ (Table 1) are calculated the same way as the amounts. First, the aliquot ratio, $R_{a}$, is calculated, as the measured ${ }^{3} \mathrm{He} /{ }^{4} \mathrm{He}$ of the sample aliquot, divided by the average of the measured ratios of the standards measured immediately before 50 and after the sample aliquot:

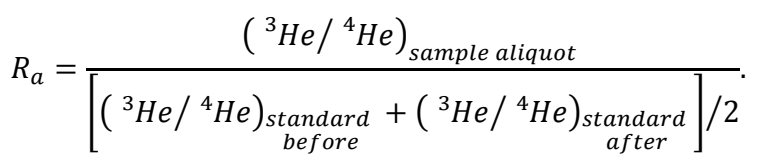

Then for each sample, the average of all of the individual $R_{a}$ are made to give the final for the sample: $R_{m}=\left(\sum_{1}^{N} R_{a N}\right) / N$. The standard errors $(2 \sigma)$ are between $0.2 \%$ and $0.3 \%$ for one sample. This error is dominated by the scatter in the ${ }^{3} \mathrm{He}$ measurement. ${ }_{55}$ For the 19 measurements shown, the average value is 1.0363 with a standard error $(2 \sigma)$ well below $0.1 \%$ at $0.0005(0.051 \%)$.

\section{Single-aliquot measurements}

To perform single-aliquot measurements, the procedure is identical to that of the multi-aliquot measurements for gas ${ }_{60}$ purification (Fig. 5). However, for the actual measurement, all of the sample gas is let into the mass spectrometer and measured at once. Two standards are measured before the sample gas, and two more after. The total time for sample preparation, standard and sample measurement is around 3 hours.

65 Table 2 Single-aliquot measurement data. The average measured ${ }^{4} \mathrm{He}$ relative to the standard $\left(\mathrm{A}_{\mathrm{s}}\right)$, the average ${ }^{3} \mathrm{He} /{ }^{4} \mathrm{He}$ relative to the standard $\left(\mathrm{R}_{\mathrm{s}}\right)$, and the standard error $(2 \sigma)$ are shown.

$\begin{array}{ccc}\mathbf{A}_{\mathbf{s}} & \mathbf{R}_{\mathbf{s}} & \text { Standard error } \mathbf{( 2 \sigma )} \\ 13.51 & 0.9238 & 0.0034 \\ 13.38 & 0.9281 & 0.0044 \\ 13.54 & 0.9273 & 0.0033 \\ 13.59 & 0.9272 & 0.0023 \\ 13.64 & 0.9264 & 0.0029 \\ 13.45 & 0.9281 & 0.0036 \\ 13.51 & 0.9288 & 0.0067 \\ 13.56 & 0.9272 & 0.0037 \\ 13.56 & 0.9269 & 0.0023 \\ 13.53 & 0.9260 & 0.0035 \\ 13.61 & 0.9252 & 0.0050 \\ 13.62 & 0.9246 & 0.0025 \\ 13.64 & 0.9281 & 0.0026 \\ 13.53 & 0.9307 & 0.0030 \\ 13.56 & 0.9243 & 0.0030 \\ 13.52 & 0.9293 & 0.0034 \\ 13.43 & 0.9236 & 0.0039 \\ & \mathbf{0 . 9 2 6 8} \pm \mathbf{0 . 0 0 1 0}(\mathbf{0 . 1 0 5} \%)-\text { standard error } \\ & \pm \mathbf{0 . 0 0 4 0}(\mathbf{0 . 4 2 \% )}-\text { standard deviation }\end{array}$


As with the multi-aliquot measurements, we show (Table 2) the amount of gas in the single sample aliquot relative to the standard $\left(A_{s}\right)$, which is the amount of ${ }^{4} \mathrm{He}$ in the sample aliquot 5 divided by the average of the two standards measured before and the two standards measured after:

$$
A_{s}=\frac{\left({ }^{4} \mathrm{He}\right)_{\text {sample }}}{\left[\sum\left({ }^{4} \mathrm{He}\right)_{\text {standards }}\right] / 4} .
$$

In contrast to the multi-aliquot method, we are not trying to match the sample size to the standard, but simply to match the amount of helium between one sample and the next. We rejected 10 any data that varied by more than $\pm 2 \%$ from the mean of all the $A_{s}$ values.

The ratio $R_{s}$ is also relative to the average ratios measured from the standards measured with the sample:

$$
R_{s}=\frac{\left({ }^{3} \mathrm{He} /{ }^{4} \mathrm{He}\right)_{\text {sample }}}{\left[\sum\left({ }^{3} \mathrm{He} /{ }^{4} \mathrm{He}\right)_{\text {standards }}\right] / 4} .
$$

The errors given for each ratio are the calculated errors based on 15 the measurement error of the five (four standards, one sample) individual measurements and are typically $0.3 \%$ to $0.4 \%$ for each single measurement. The mean for these 17 measurements is 0.9268 with standard error is $0.001(0.1 \%, 2 \sigma)$. Note that this ratio differs from the multi-aliquot ratio (by $\sim 11 \%$ ). This is a 20 consequence of the pressure effect discussed above; although both are normalized to the same internal standard, the singlealiquot measurements have about 13.5 times more gas than the multi-aliquot measurements.

\section{Discussion}

${ }_{25}$ For purposes of comparing these two measurement methods, we have normalized these two data sets to their respective mean values and show them together in Fig. 6. Each point represents approximately the same total amount of sample gas measured. The multi-aliquot method has noticeably less amount of scatter 30 and the standard deviation is half that of the single-aliquot data.

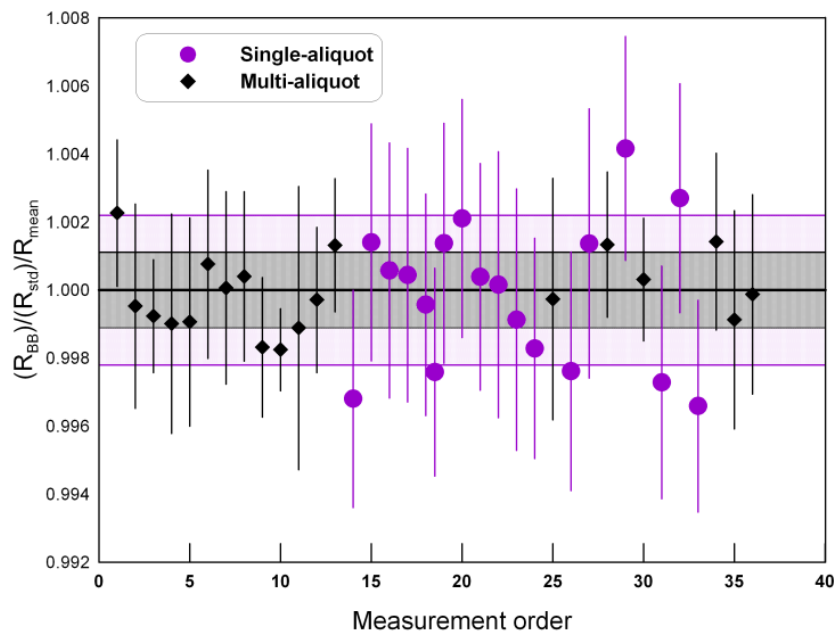

Fig. 6 Normalized measured ratios for the single-aliquot (purple circles) and multi-aliquot (black diamonds) method, shown in the order in which they were measured. The inner shaded region represents one standard 35 deviation for the multi-aliquot measurements, while the out shaded region is one standard deviation for the single-aliquot measurements.

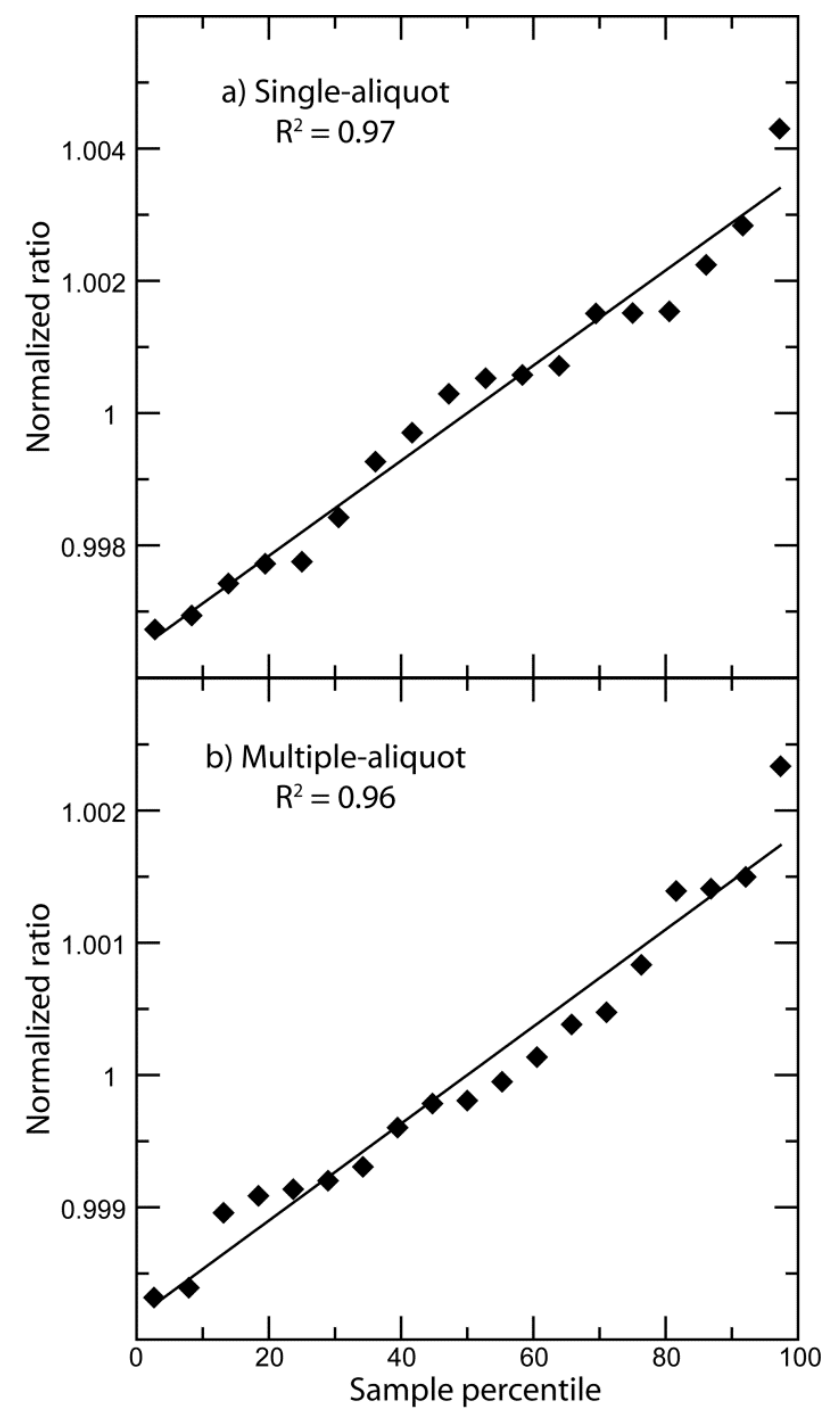

Fig. 7 Normal probability plot for (a) single-aliquot and (b) multi-aliquot 40 ratio measurements.

To determine whether or not the difference between these two methods is statistically significant, we make a one-tailed F-test. First, for the test to be valid the data sets should be normally distributed, so we make a normal probability plot for each data ${ }_{45}$ set (Fig. 7) and check that the result is linear. We use a one-sided test because we developed the multi-aliquot method specifically to improve upon the single-aliquot method. The details of this calculation are shown in Table 3 and indicate that the lower variance of the multi-aliquot method compared to the single50 aliquot method is statistically significant at a $95 \%$ confidence level. 
Table 3 One-tailed F-test calculation comparing the standard deviations of the multi-aliquot $\left(\mathrm{S}_{\mathrm{m}}\right)$ and single-aliquot $\left(\mathrm{S}_{\mathrm{s}}\right)$ measurements. The calculation indicates that the difference between them is significant.

\begin{tabular}{ll}
\hline Formulate null and alternative & $\mathrm{H}_{0} \rightarrow \mathrm{S}_{\mathrm{m}}{ }^{2}=\mathrm{S}_{\mathrm{s}}{ }^{2}$ \\
hypotheses & $\mathrm{H}_{1} \rightarrow \mathrm{S}_{\mathrm{m}}{ }^{2}<\mathrm{S}_{\mathrm{s}}{ }^{2}$ \\
\hline Calculate $\mathrm{F}$ & $\mathrm{F}=\mathrm{S}_{\mathrm{s}}{ }^{2} / \mathrm{S}_{\mathrm{m}}{ }^{2}=(0.00200)^{2} /(0.00111)^{2}$ \\
& $=3.2465$ \\
\hline Critical F value for $\alpha=0.05$ & $\mathrm{~F}_{\text {crit }}=2.2496$ \\
Is F $>\mathrm{F}_{\text {crit }}$ ? & $3.2465>2.2496 \checkmark$ \\
\hline
\end{tabular}

In a direct comparison, for the same total amount of gas measured, but different total measurement times, the multialiquot method has errors on a single sample of about $60 \%$ of the single-aliquot method and a long term reproducibility that is about twice as good. Although it seems obvious that increasing 10 the measurement time will improve the statistics, this is not always the case. A significant increase in measurement time, such as in this case, increases the probability that external factors (drift in electronics, gain of detectors, temperature, day/night variations) may affect the measurement and thus hinder an 15 improvement in statistics.

Next, there is the question of whether the improvement is worth the extra measuring time. This depends on several factors such as the time available for measurements, the precision needed, and the number of samples available. Based on these

20 data, it takes only on average 3 separate sample measurements by the multi-aliquot method to reach a standard error of $0.1 \%(2 \sigma)$ for a total laboratory time around 30 hours. In contrast, the single-aliquot method approached a plateau at an average standard error of $0.11 \%(2 \sigma)$ after 11 separate samples measured 25 (total laboratory time $\sim 33$ hours). Thus, if reaching $0.1 \%$ precision is important, the multi-aliquot method is the better choice, especially if one is limited in the number of samples one can acquire.

Finally, we have made measurements using the multi-aliquot 30 method over an extended time period beyond this comparison study in order to assess the long-term reproducibility. The measurements made over a period of about 270 days were very stable (Fig. 8), with no trend detected; a linear fit gives an $\mathrm{R}^{2}=$ 0.0012. This time period includes the replacement of the 35 multiplier around day 200 (necessitating opening the mass spectrometer to atmosphere).

The $2 \sigma$ standard error over this entire period is $0.033 \%$. The earliest measurements (first 30 days) have a higher amount of scatter $(\mathrm{SD}=0.41 \% 2 \sigma)$ compared to later measurements $(\mathrm{SD}=$ $400.27 \% 2 \sigma)$. We attribute this to the fact that the first measurements were made soon after the installation of the new mass spectrometer and some details were still being finalized such as climate control of the laboratory.

\section{Conclusions}

45 We have constructed an extraction line to purify relatively large quantities of atmospheric helium and monitor the consistency of the purification process with a quadrupole mass spectrometer. An adjustable volume is used to control the quantity of this helium to be let into the mass spectrometer and thus mitigate pressure ${ }_{50}$ effects in the source. A cryogenic trap on the line removes the neon from the sample gas for further control of the pressure in the mass spectrometer. The addition of a second cryogenic trap on the mass spectrometer volume maintains low and stable background levels which are essential for high precision helium 55 isotope measurements.

We compared our modified multi-aliquot measurement method to the more 'traditional' single-aliquot method. In both cases we monitor and control the amount of gas let in for a measurement. We found a 2x improvement in the error when using the multi${ }_{60}$ aliquot measurement technique over the single-aliquot method. With the multi-aliquot measurement technique, we can measure with a long-term reproducibility over several months of $0.033 \%$ $(2 \sigma)$. Single measurements have standard errors of 0.2 to $0.3 \%$ $(2 \sigma)$, but only three replicate samples are needed to reach $0.1 \%$ or ${ }_{65}$ better errors. This is a level sufficient to probe further into the question of temporal helium isotopic variations.

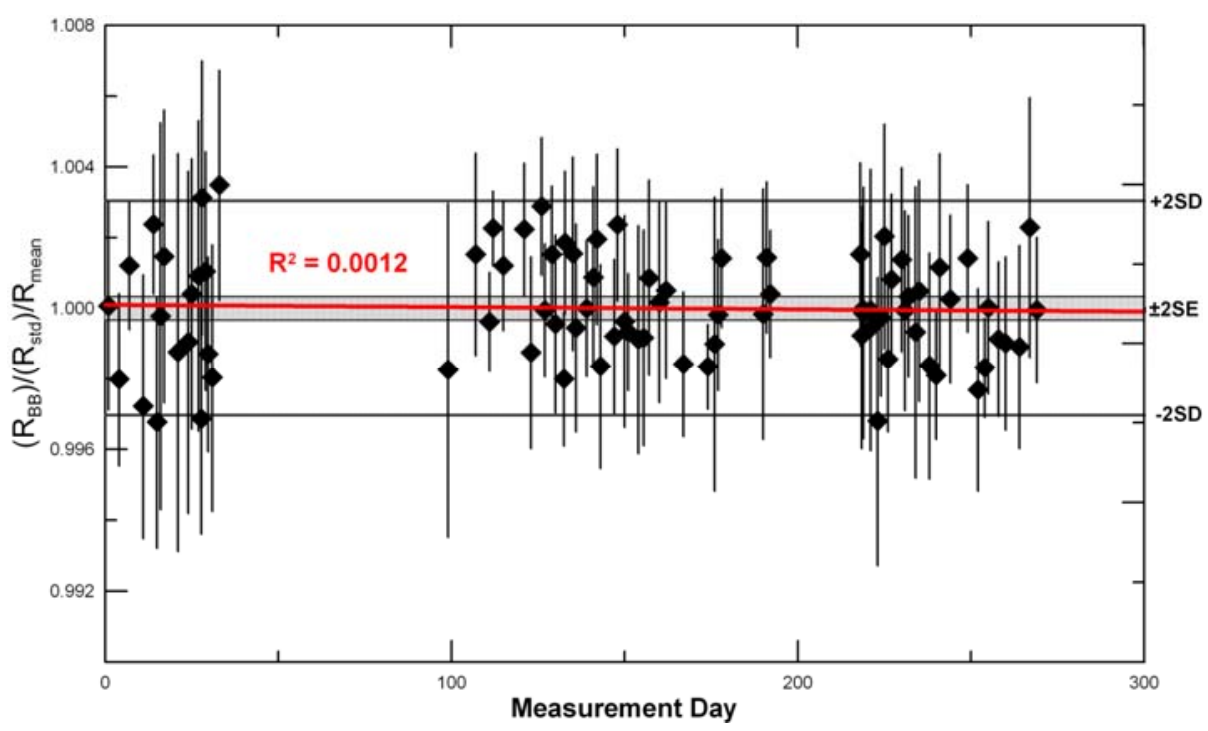

Fig. 8 All (83) multi-aliquot measurements made over 270 days. The red line is a linear fit of the data and shows no significant trend over time. The grey 70 shaded area shows 2 standard errors (SE) and the thick black lines show 2 standard deviations (SD). 


\section{Acknowledgments}

This experiment is funded by grant VIHA2 from the Agence Nationale de la Recherche (ANR), and by the European Research Council under the European Community's Seventh Framework 5 Programme (FP7/2007-2013 grant agreement no. 267255).

\section{Notes and references}

${ }^{a}$ CRPG-CNRS, 15 rue Notre Dame des Pauvres, Vandoeuvre-les-Nancy,

France.E-mail:jmabry@crpg.cnrs-nancy.fr

10 1. E. Gluckauf, Proceedings of the Royal Society A: Mathematical, Physical and Engineering Sciences, 1946, 185, 98-119.

2. G. Kockarts and M. Nicolet, Ann. Geophys., 1962, 18, 269-290.

3. T. Torgersen, Chemical Geology: Isotope Geoscience section, 1989, 79, $1-14$.

15 4. Y. Sano, B. Marty, and P. Burnard, in The Noble Gases as Geochemical Tracers, ed. P. Burnard, Springer, 2013, pp. 17-31.

5. B. M. Oliver, J. G. Bradley, and H. Farrar IV, Geochimica et Cosmochimica Acta, 1984, 48, 1759-1767.

6. A.-C. Pierson-Wickmann, B. Marty, and A. Ploquin, Earth and Planetary Science Letters, 2001, 194, 165-175.

7. Y. Sano, Y. Furukawa, and N. Takahata, Geochimica et Cosmochimica Acta, 2010, 74, 4893-4901.

8. Y. Sano, H. Wakita, Y. Makide, and T. Tominaga, Geophysical Research Letters, 1989, 16, 1371-1374.

25 9. Y. Sano, Journal of Science of the Hiroshima University, 1998, 11, 113-118.

10. J. Lupton and L. Evans, Geophys. Res. Lett., 2004, 31, 4.

11. J.-I. Matsuda, T. Matsumoto, and A. Suzuki, Geochemical Journal, 2010, 44, e5-e9.

30 12. M. S. Brennwald, N. Vogel, S. Figura, M. K. Vollmer, R. Langenfelds, L. Paul Steele, C. Maden, and R. Kipfer, Earth and Planetary Science Letters, 2013, 366, 27-37.

13. Y. Sano, T. Tokutake, and N. Takahata, Analytical sciences: The international journal of the Japan Society for Analytical Chemistry, 2008, 24, 521-5.

14. R. Piazza, Soft Matter, 2008, 4, 1740.

15. D. S. Tomar, M. Singla, and S. Gumma, Microporous and Mesoporous Materials, 2011, 142, 116-121.

16. P. G. Burnard and K. A. Farley, Geochemistry Geophysics 40 Geosystems, 2000, 1, 1022. 